\title{
PRESERVAÇÃO DO MATERIAL BIBLIOGRÁFICO DA BIBLIOTECA HUGO DANTAS DA SILVEIRA - UNIVERSIDADE FEDERAL DO RIO GRANDE - FURG
}

\author{
MARIA HELENA MACHADO DE MORAES* \\ VANESSA DIAS SANTIAGO**
}

\begin{abstract}
RESUMO
O presente trabalho buscou discutir a necessidade de ações educativas para o uso correto do material bibliográfico da Biblioteca Hugo Dantas da Silveira. Devido as constantes observações de materiais com problemas de mau uso, foram planejadas medidas que demonstrem aos usuários a necessidade de cuidar do acervo da biblioteca. Estas ações apontam que trabalhar os processos de preservação, visando prolongar a vida útil e o uso coletivo desses materiais, são relevantes para qualquer biblioteca. Observou-se também que estes processos são responsabilidade tanto da unidade de informação e seus profissionais quanto dos usuários que fazem uso do material bibliográfico. Como medidas para sensibilizar o usuário em relação aos danos causados nesses materiais, a equipe do atendimento criou marca páginas tendo no verso informações de cuidados com os itens. Assim como exposição de livros danificados no interior da biblioteca, assinalando que riscar, marcar, rasgar, molhar ou manchar os itens prejudica o uso e a qualidade do conteúdo. Neste sentido acredita-se que é preciso educar para preservar e espera-se que essas ações impactem positivamente na redução de danos a coleção desta biblioteca.
\end{abstract}

PALAVRAS-CHAVE: Biblioteca Universitária. Preservação. Material bibliográfico.

\section{ABSTRACT}

The present study sought to discuss the need for educational actions for the correct use of bibliographic material from the library Hugo Dantas da Silveira. Because of the constant observations of materials with problems of misuse, were planned measures which demonstrate to users need to take care of the library. These actions indicate that work the processes of preservation, aiming to prolong the useful life

* Doutora em Educação em Ciências. Bibliotecária do Setor de Referência da Biblioteca Hugo Dantas da Silveira. Sistema de Bibliotecas da Universidade Federal do Rio Grande - FURG.

** Especialista em Gestão de Projetos. Bibliotecária chefe da Biblioteca Hugo Dantas da Silveira. Sistema de Bibliotecas da Universidade Federal do Rio Grande - FURG. 
and the collective use of these materials, are relevant for any library. It was also observed that these processes are the responsibility of both the information unit and its professionals and users who make use of bibliographic material. As measures to sensitize the user in relation to the damage caused to these materials, the team of care created brand pages with information on the back of care with items. As well as exposure of damaged books inside the library, noting that scratch, Mark, tearing, wet or tarnish the items affect the use and the quality of content. In this sense we believe that we must educate to preserve and it is expected that these actions impact positively on harm reduction the collection of this library.

KEYWORDS: University Library. Preservation. Bibliographic material.

\section{INTRODUÇÃO}

As bibliotecas universitárias, entre tantas características, trazem consigo a responsabilidade social de acesso e uso do conhecimento produzido. Fato que ocorre através da disponibilidade de seus acervos bibliográficos e no auxilio as mais diferentes pesquisas e serviços de busca e recuperação da informação. Todavia, para atender de maneira eficiente seu público, demanda cuidados diários na preservação de todo o material bibliográfico que compõe seu acervo.

Preservar 0 acervo das bibliotecas precisa constar no planejamento dos gestores, uma vez que, nem sempre existem verbas para aquisição de novos materiais. A preservação preventiva com cuidados cotidianos, como o manuseio e o bom uso, são formas de evitar a remoção de obras do acervo da unidade.

Os processos de preservação incluem toda a coleção que faz parte da biblioteca, do impresso as mídias digitais, há necessidade de zelar pelo material bibliográfico de qualquer biblioteca. Ações educativas são relevantes nestes casos, somente com o entendimento do valor, neste contexto, a riqueza do conhecimento, é que podem acontecer ações que amenizem os processos de danificação do material circulante.

Entende-se que o uso diário da obra causa desgaste, fato esperado, o que questiona-se é o descuido no manuseio, é expor a obra a chuva, umidade, alimentos e bebidas danificando o item. Usar materiais como clips e fitas adesivas para marcar ou simplesmente grifar o livro, com anotações pessoais. Lembrando que o acervo de uma biblioteca é de uso coletivo, voltado para o acesso de toda comunidade. $\mathrm{E}$ no momento que há descuido, o material deixa de circular, para que seja verificado se é possível 
consertar o dano ou se o mesmo deve ser descartado, com o laudo de deteriorado/danificado.

Com o objetivo de reduzir os problemas de mau uso do material bibliográfico, foram planejadas ações com o intuito de alertar os usuários sobre a importância do cuidado com o acervo da biblioteca, mantendo assim a integridade do documento. Compreendendo que o uso é coletivo e que preservando todos terão acesso.

\section{BIBLIOTECA HUGO DANTAS DA SILVEIRA}

A história da Biblioteca entrelaça-se com a da própria instituição, no contexto de criação e crescimento. Como consta no histórico da biblioteca ${ }^{1}$ por conta de mudanças de infraestrutura e local, cursos da instituição foram transferidos para novo local e com isso movimentou-se o acervo bibliográfico também. Apenas na década de 80 é que foi construído prédio próprio da biblioteca, no qual permanece até os dias atuais.

No ano de 2009, com o crescimento da instituição, com a oferta de mais cursos e consequente aumento do acervo bibliográfico o prédio passou por processo de ampliação, já no ano de 2010, com as mudanças organizacionais e de infraestrutura o Núcleo de Informação e Documentação (NID), como era conhecido antes as bibliotecas da instituição, passou a denominar-se Sistema de Bibliotecas ( $\mathrm{SiB}$ ), que comporta a Biblioteca Central e sete bibliotecas setoriais.

Atualmente a Biblioteca Hugo Dantas da Silveira conhecida como Biblioteca Central, atende cursos de graduação e pós-graduação, assim como servidores e a comunidade externa. Conta em seu acervo com diversos tipos de materiais como livros, periódicos, folhetos, CD/DVD, bases de dados, mapas, obras em Braille, entre outros, atendendo a necessidade de todas as áreas do conhecimento.

Nesta unidade, circulam por mês em torno de 15 mil usuários $^{2}$, nos três turnos de funcionamento. Fato que demonstra a alta circulação e uso do material bibliográfico que compõe a coleção da biblioteca. Neste contexto são necessários processos educativos que mobilizem os usuários e profissionais da unidade para a preservação desses materiais.

\section{PRESERVAÇÃO DO MATERIAL BIBLIOGRÁFICO DA}

\footnotetext{
${ }_{1}^{1}$ Para outras informações acesse http://www.biblioteca.furg.br/pt/biblioteca-central.

2 Estimativa feita no mês de novembro de 2017, a partir das antenas de acesso a Biblioteca Hugo Dantas da Silveira da Universidade Federal do Rio Grande - FURG.
} 


\section{BIBLIOTECA UNIVERSITÁRIA HUGO DANTAS DA SILVEIRA}

A biblioteca universitária está comprometida com os processos de ensino e aprendizagem de qualquer instituição, podendo vir a mediar estudos e pesquisas que vão além da sala de aula. Assim como os processos sociais perpassam por estes espaços, uma vez que é responsável pela divulgação e a promoção da informação de todas as áreas do saber. Fonseca (2007, p. 61) comenta que biblioteca universitária é;

[...] aquela que serve aos propósitos das universidades e instituições de ensino superior. Sua finalidade é atender a estudos, consultas e pesquisas de alunos, e professores universitários. Deve funcionar como verdadeiro centro de documentação, e estar integrada à universidade. Correspondem à unidade de informação de uma Universidade, pelo que as suas coleções devem refletir as matérias lecionadas nos cursos e áreas de investigação da instituição.

Neste sentido o material bibliográfico utilizado tanto para estudo quanto para a pesquisa pode ser visto como uma ferramenta que para funcionar precisa apresentar bom estado de uso, fato este que impele ações de cuidados constantes. Compreende-se que a vida de um livro é alterada toda vez que o mesmo é usado, deve-se usá-lo, mas há diferença no dano pelo excesso de uso e o dano pela falta de cuidados básicos com o material.

Ao circular o material pode passar por processos que o deterioram como exposição a chuva, umidade e alimentos, e em sua maioria, estes processos poderiam ser evitados, se os usuários entendessem que devem cuidar dos materiais que estão sob sua responsabilidade. Assim como marcações, grifos, uso de fitas adesivas, clips e marca textos, mão sujas, cigarros entre outros que impactam na vida útil do livro.

$\mathrm{E}$ por vezes, não há compreensão dos problemas que causam no acervo e do prejuízo aos demais usuário que precisam utilizar o mesmo item. Ao abrir um livro para ler e/ou estudar é frustrante encontrar diversas anotações, sejam a lápis ou canetas, com ideias de terceiros, tirando a atenção do leitor e impactando no seu entendimento.

Neste contexto, discute-se muito sobre a preocupação das bibliotecas em preservar e conservar seu acervo, a fim de ampliar a vida útil do mesmo. Observa-se que as bibliotecas, independente de 
seu objetivo, têm como premissa, em relação ao uso do acervo, preservar e conservar. Pois se tem a dificuldade de aquisição de novos materiais, em geral, as instituições públicas dependem de verba governamental para qualquer processo de aquisição, e nem sempre há financiamento para compra de material bibliográfico, tanto para atualização quanto reposição.

Pode-se dizer que a preservação de um acervo consiste em um conjunto de atitudes exercidas tanto pelas instituições quanto pelos usuários destas. Para este processo, primeiramente é necessário compreender os conceitos de preservação e conservação, conforme Cassares (2000, p. 12);

\begin{abstract}
Preservação: É o conjunto de medidas e estratégias de ordem administrativa, política e operacional que contribuem direta ou indiretamente para a proteção do patrimônio.

Conservação: É o levantamento, estudo e controle das causas de degradação, permitindo a adoção de medidas de prevenção. É um procedimento prático aplicado na preservação.

Conservação Preventiva: São intervenções diretas, feitas com a finalidade de resguardar o objeto, prevenindo possíveis malefícios.
\end{abstract}

Entende-se que preservar é um ato educativo, é desenvolver ações que busquem orientar os cuidados com o acervo. A gestão da biblioteca deve ter a preocupação em desenvolver políticas que amenizem os problemas de deterioração do acervo, enfatizando a importância do material para o usuário. Para Coradi; Eggert-Steindel (2008, p. 355) "para prolongar a vida útil ou impedir a deterioração de livros e documentos, é necessário que o acervo siga um programa de preservação e conservação, a fim de manter a integridade física de seus volumes".

Processos de conservação e restauração dependem de profissionais especializados na área, por isso a preservação preventiva é importante, pois "é uma atividade técnica de baixo custo financeiro e de fácil implementação". (MÁRSICO, 2009). Sobre preservação Antunes (2010) comenta que é a "garantia de integridade e perenidade de algo que se reconhece como tendo valor, defendendo-o de riscos e danos. Implica a definição de política específica para esse fim".

É preciso compreender que o material bibliográfico é fonte inestimável de valor, e a biblioteca conta em sua coleção diferentes materiais com saberes únicos. Sendo que os 
processos de preservação são responsabilidade de cada unidade de informação que tem como objetivo a disseminação do conhecimento.

Segundo o Dicionário Aurélio (2010, p. 562) a conservação consiste na condição ou aspecto daquilo que, graças a cuidados especiais resiste mais ou menos ao processo de desgaste. Já a preservação de acordo com Milevski (1997, p. 14) consiste em;

[...] inúmeras políticas e opções de ação, incluindo tratamentos de conservação. Preservação é a aquisição, organização e distribuição de recursos a fim de que venham a impedir posterior deterioração ou renovar a possibilidade de utilização de um seleto grupo de materiais [...].

Preservar, neste pensar, está relacionado às políticas desenvolvidas pelas bibliotecas que visem orientar os usuários, através de campanhas ou projetos de preservação, quanto ao uso e manuseio do material. Já a conservação implica em métodos adotados pelas bibliotecas para conservar o material que poderá sofrer danos por agentes físicos e biológicos, tais como: radiação ultravioleta, temperatura e umidade relativa, poluição, microorganismos, insetos entre outros.

Assim como as pessoas, os livros também têm um ciclo de vida útil, que vai desde sua criação até o momento em que, devido a diversos fatores (biológicos ou físicos) não podem mais ser utilizados. Aponta-se a necessária adoção de processos de preservação no cotidiano da circulação de materiais, prolongando a vida útil do acervo e colaborando com o acesso de novos usuários.

As bibliotecas universitárias estão interligadas a todo processo de ensino e aprendizagem de uma instituição, esperase que medidas educativas consigam expor que é relevante preservar o acervo para ser ter acesso ao conhecimento produzido, a memória e a cultura.

\section{METODOLOGIA}

A partir das observações do material bibliográfico circulante na Biblioteca Hugo Dantas da Silveira, constatou-se uma quantidade significativa de materiais danificados pelo do mau uso. São atitudes rotineiras que provocam degradação do item, causando impactos financeiros à instituição e prejuízo de acesso 
aos demais usuários.

No cotidiano dos serviços, é visível a devolução de materiais molhados, úmidos, sujos, manchados, grifados, marcados, rasgados, folhas arrancadas e até mesmo capítulos entre outros, causando a retirada do material do acervo para restauro ou descarte. Fato que impacta no direito de uso dos demais membros da comunidade em geral. Com a ideia de alterar essas práticas, ações estão sendo desenvolvidas, aproximando o usuário da realidade da biblioteca e do material bibliográfico. São propostas de criação de vídeos, uso das redes sociais, marca páginas e diálogos para entender a necessidade de cuidar do material utilizado.

Também se lançou a proposta de exposição de materiais danificados, sendo que já aconteceu no ano de 2017 e será relançada em outubro do ano de 2018. Assim como, optou-se por fazer anotações no Sistema de Administração de Bibliotecas ARGO, tanto na retirada como na devolução sobre qualquer alteração no estado físico da obra.

\section{AÇÕES EDUCATIVAS PARA PRESERVAÇÃO DO MATERIAL BIBLIOGRÁFICO}

Ações educativas no que se refere ao uso do material bibliográfico do acervo da Biblioteca Hugo Dantas da Silveira são necessárias. Como discutido até o momento, são problemas diários que afetam a integridade do material, causando impactos negativos para a instituição e para todos os usuários que dependem deste material para seus estudos e pesquisas.

A partir dos processos do setor de circulação de materiais da biblioteca, é possível acompanhar a devolução de obras, com danos visíveis, ao atendente. Em geral, são problemas de descuido com as obras emprestadas. Na Figura 1 apresentam-se 3 livros que foram entregues molhados ou manchados no balcão de atendimento.

FIGURA 1 - Livros manchados por café, chá doce e livro 
molhado, entregues na biblioteca.
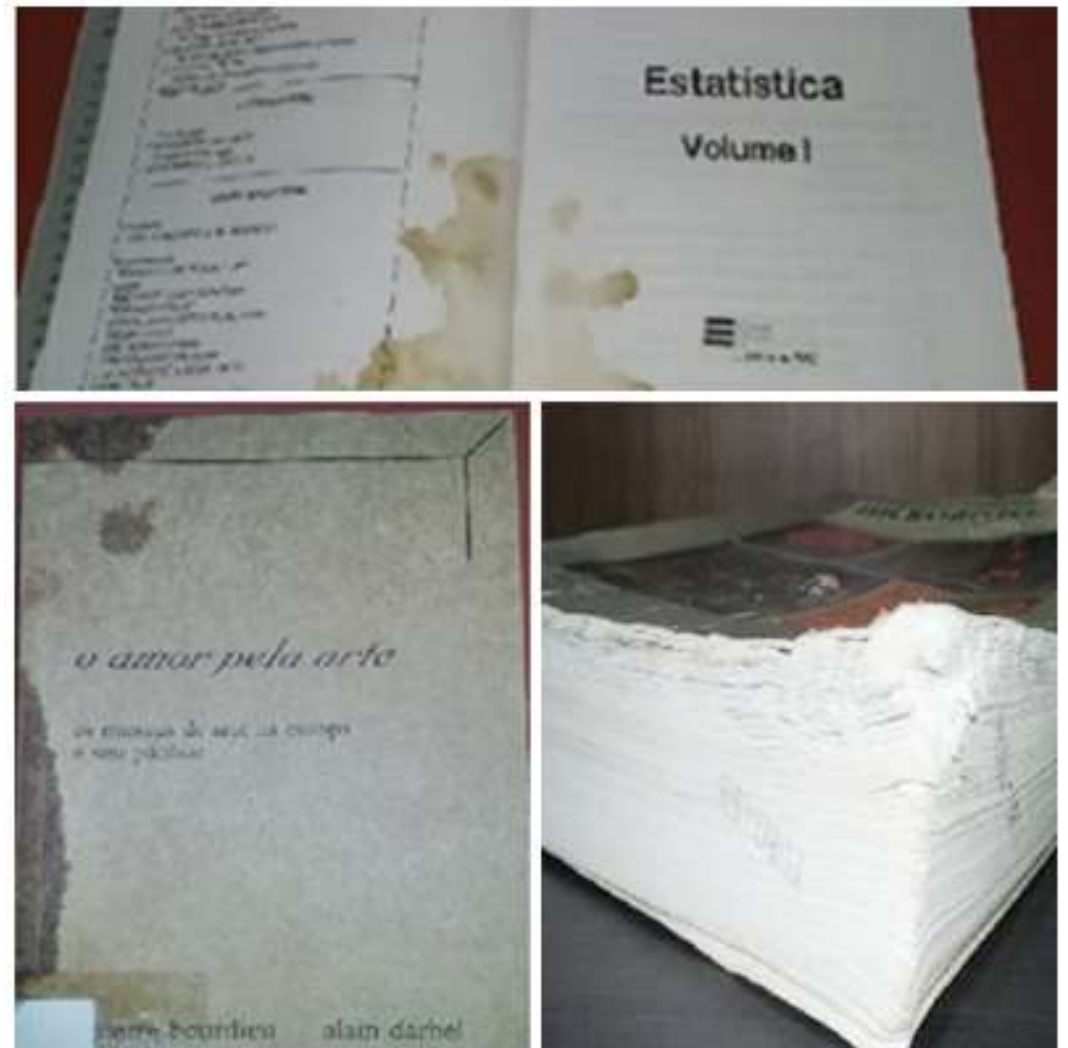

FONTE: Biblioteca Hugo Dantas da Silveira

Os livros apresentados na Figura 1 foram entregues no balcão de atendimento da biblioteca. Conforme observa-se nas fotos os livros estão danificados e sem condições de voltar para o acervo. Aos usuários que entregam livros danificados é informado a necessidade de reposição da obra, seguindo as regras que constam no regulamento interno do Sistema de Bibliotecas. Todo usuário deve repor o material em caso de extravio ou dano, todavia, nem sempre os usuários realizam a reposição, e as obras acabam sendo retiradas da coleção.

Ingerir café e chá utilizando os materiais da biblioteca, são fatores que os usuários sempre são alertados, pois se entornarem na obra o estrago é certo e não tem como amenizar problemas desta 
ordem. Os livros com manchas desta natureza, são retirados do acervo até que haja a reposição de outro exemplar.

Em dias de chuva é fator comum à devolução de materiais molhados, tornando-se o "guarda-chuva" para alguns, que não entendem o quão prejudicial é molhar o livro. Seguindo procedimento da biblioteca obras molhadas, quando não há como restaurar, recebe o status de danificado e não pode voltar ao acervo. Na Figura 2 têm-se exemplos de outros danos causados pelos usuários como livros grifados, mordidos por animais de estimação e com substâncias estranhas ou não identificados.

FIGURA 2 - Livro grifado, danificado pelo animal de estimação e mancha não identificada.

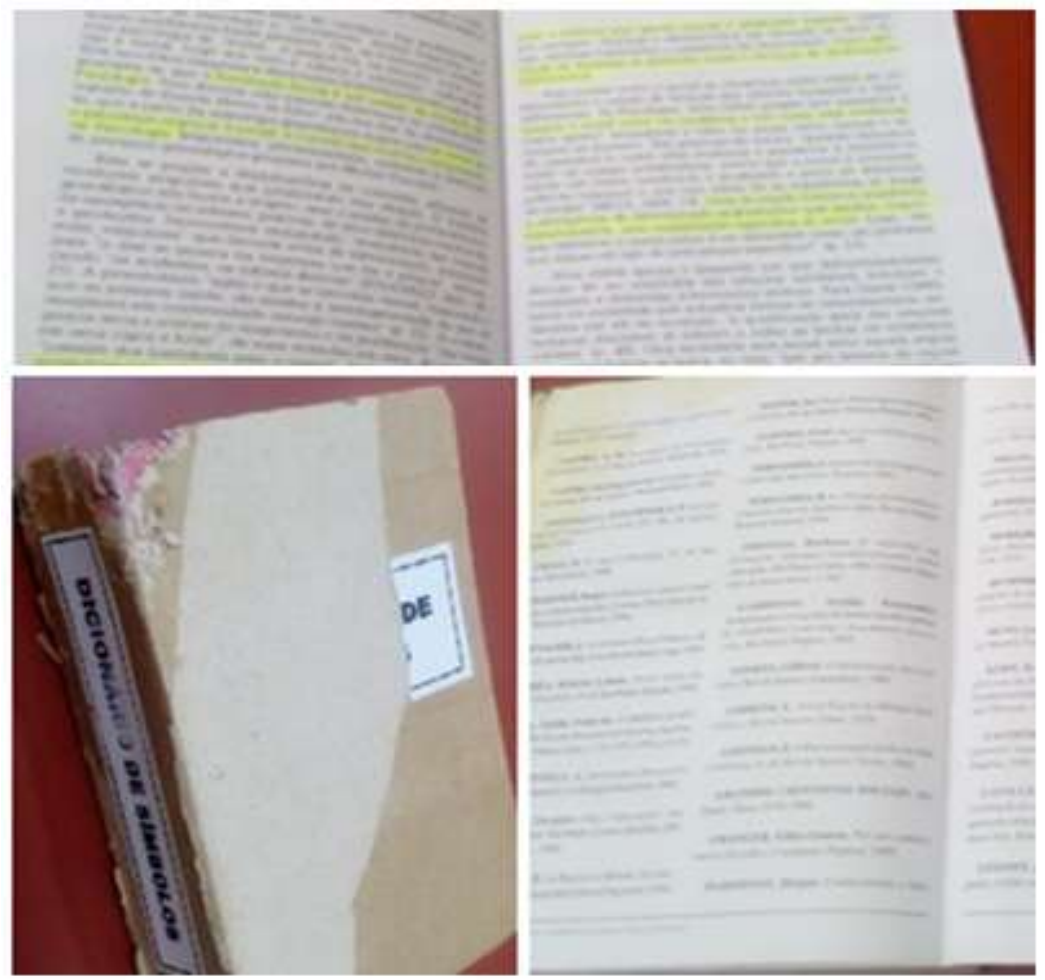

FONTE: Biblioteca Hugo Dantas da Silveira

Conforme apresentado na Figura 2, danos de toda natureza acontecem, por isso a necessidade de desenvolver campanhas educativas sobre a importância de a comunidade acadêmica zelar 
pelos materiais utilizados, a fim de prolongar a vida útil do mesmo. $\mathrm{O}$ livro grifado era um livro novo que foi adquirido recentemente, e por ter sido marcado de maneira que não se pode restaurar, retirou-se de circulação do acervo corrente, até que seja resposto pelo usuário que o grifou.

O livro mordido pelo animal de estimação é um material que já tinha passado por um processo de restauro, e novamente foi danificado; cabe salientar que este livro é de difícil reposição e atualmente encontra-se fora de circulação, até que seja resposto pelo usuário que estava com a obra. O terceiro livro da figura não foi identificado o que causou a mancha e o usuário não informou o ocorrido no momento da devolução, mas ressalta o odor desagradável da obra.

Fica visível que o material bibliográfico não é preservado quanto ao seu uso, talvez não haja compreensão de sua importância no processo de ensino aprendizagem e nem do valor científico e financeiro do mesmo. A fim de diminuir esses problemas enfrentados frequentemente, é premente desenvolver ações educativas em relação ao uso e cuidados para que a obra continue em circulação.

Após a exposição dos problemas em relação ao material bibliográfico circulante na biblioteca, optou-se em distribuir marca páginas com informações sobre os cuidados com o acervo e atividades que demonstrem que ao danificar as obras todos são prejudicados.

FIGURA 3 - Marca página sobre cuidados com as obras

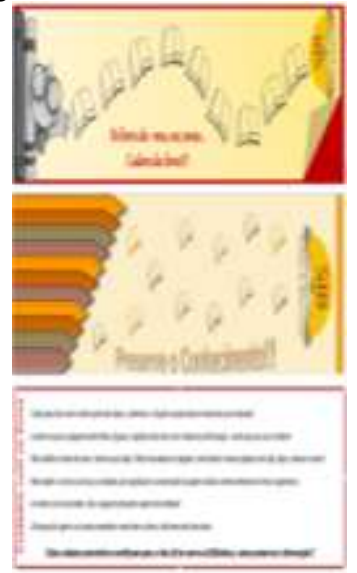

FONTE: Material desenvolvido pelo setor de atendimento da biblioteca Hugo Dantas da Silveira

Os marca páginas foram criados pelos bibliotecários que 
atuam no setor de atendimento da biblioteca Hugo Dantas da Silveira, os mesmos são entregues em conjunto com os livros no momento do processo de empréstimo de materiais, com isso, espera-se que possamos sensibilizar a comunidade, a fim de que não sejam utilizados outros acessórios para marcar as leituras.

No verso dos marca páginas contêm informações sobre os cuidados que se devem ter ao manusear o material bibliográfico. Esse material é para circular sempre com as obras, com a expectativa de diminuir o descuido que tem acontecido.

Com a premissa de apresentar à comunidade problemas causados pela falta de zelo/cuidados com o acervo da biblioteca, também foi organizado uma exposição de materiais bibliográficos danificados, conforme exposto na Figura 4.

FIGURA 4 - Exposição de material bibliográfico danificado no ano de 2017

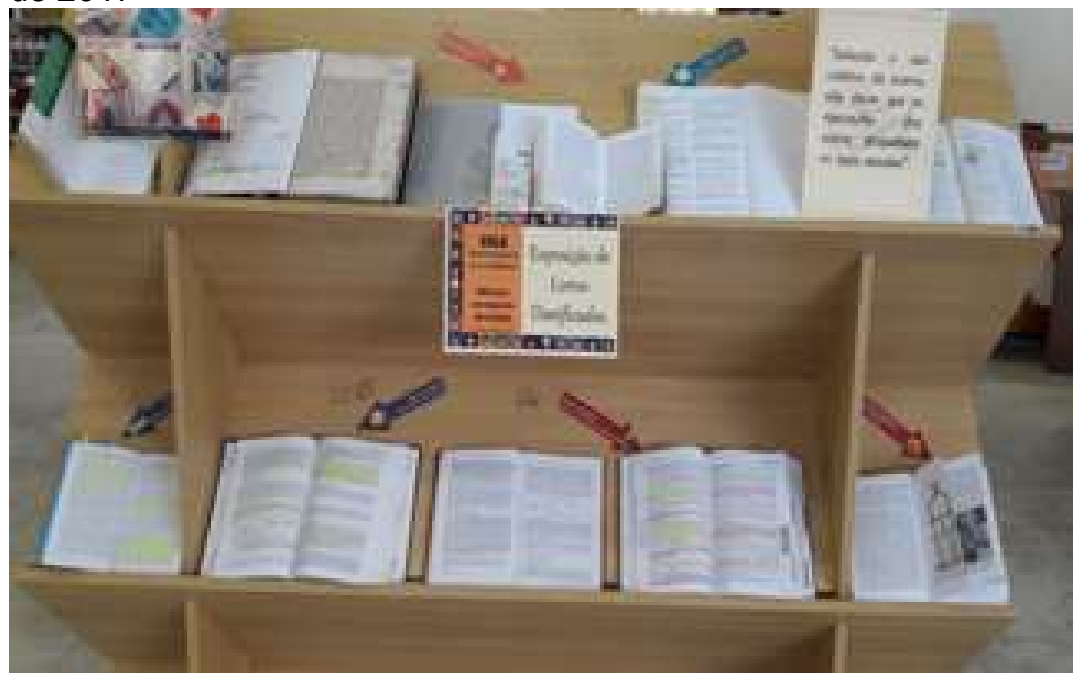

FONTE: Biblioteca Hugo Dantas da Silveira

A proposta da exposição de materiais danificados aconteceu durante a Semana Nacional do Livro e da Biblioteca no ano de 2017, organizada na entrada da biblioteca Hugo Dantas da Silveira, podendo ser visualizada por todos os usuários da instituição. Foram três expositores que apresentavam os inúmeros livros danificados e ressaltava que o bom uso do material é responsabilidade de todos.

A exposição de obras danificadas ocorrerá novamente no ano 
de 2018, pois ainda há necessidade de sensibilizar os usuários da unidade, e com isso diminuir os problemas que o setor de circulação aponta em relação aos materiais devolvidos danificados.

\section{CONSIDERAÇÕES FINAIS}

Preservar é cuidar do material bibliográfico, é permitir que o acesso ao conhecimento se encontre ao alcance de cada usuário que requisitar, em bom estado, sem interferência de danos causados por terceiros. É pensar no futuro e imaginar o acervo para aqueles que ainda chegarão a universidade e que a biblioteca será o espaço para seus estudos e pesquisas.

Ao discutir a necessidade de preservação da coleção da biblioteca Hugo Dantas da Silveira, buscou-se apontar os muitos problemas que, em geral, as bibliotecas lidam cotidianamente. Independente se biblioteca escolar, universitária ou pública urge a necessidade de propostas de aproximação do público com os serviços e produtos disponibilizados e seus devidos cuidados.

É importante desenvolver ações que eduquem os usuários sobre suas responsabilidades em relação ao manuseio do acervo, é planejar unidades comprometidas com a preservação do saber. Observa-se também que a preservação não é somente de livros, que na era digital são inúmeros suportes que disponibilizam conhecimentos e precisam ficar resguardados.

Observa-se que é relevante conhecer as causas que impactam na degradação do acervo das bibliotecas, desde fatores naturais, biológicos até ao descomprometimento do usuário que utiliza os produtos para seus estudos pesquisas e lazer. A partir dessas informações, desenvolver ações que mobilizem toda comunidade.

Por fim, espera-se que aconteçam trocas de experiências entre as unidades de informação, com o intuito de fortalecer a ideia que é preciso salvaguardar o conhecimento e todos são responsáveis pelo processo.

\section{REFERÊNCIAS}

ANTUNES, Margaret Alves. Pequenos reparos em material bibliográfico. São Paulo: Secretaria de Estado da Cultura de São Paulo, 2010. Disponível em: https://spleituras.org.br/wp-content/uploads/2015/06/NOTAS-DE-BIBLIOTECAN-2.pdf. Acesso em: 18 jun. 2018.

CASSARES, Norma Cianflone. Como fazer conservação preventiva em arquivos e bibliotecas. São Paulo: Arquivo do Estado e imprensa oficial, 2000. 
CORADI, Joana Paula; STEINDEL, Gisela Eggert-Steindel. Técnicas básicas de conservação e preservação de acervos bibliográficos. Revista ACB: Biblioteconomia em Santa Catarina, Florianópolis, v. 13, n. 2, p. 347-363, 2008. Disponível em: https://revista.acbsc.org.br/racb/article/viewFile/588/693. Acesso em: 04 jul. 2018.

FERREIRA, Aurélio Buarque de Holanda; FERREIRA, Marina Baird, Margarida dos Anjos (Coord.). Dicionário Aurélio da língua portuguesa. 5. ed. - Curitiba: Positivo, 2010. 2222 p.

FONSECA, Edson Nery da. Introdução à Biblioteconomia. São Paulo: Pioneira, 2007.

MÁRSICO, Maria Aparecida de Vries. Noções básicas de conservação de livros e documentos. Disponível em: https://simagestao.com.br/wpcontent/uploads/2016/05/Nocoes-Basicas-de-Conservacao-de-Livros-eDocumentos.pdf Acesso em: 24 jun. 2018.

MILEVSKI, Robert. J. Manual de pequenos reparos em livros. Rio de Janeiro: Arquivo Nacional, 1997. 